\title{
When Pandemics Call: Community-Based Research Considerations for HIV Scholars
}

\author{
ljeoma Opara ${ }^{1,6} \cdot$ Cristian J. Chandler ${ }^{2,6} \cdot$ Danielle C. Alcena-Stiner ${ }^{3,6} \cdot$ Nkiru A. Nnawulezi $^{4,6} \cdot$ Trace S. Kershaw $^{5,6}$
}

Published online: 24 April 2020

○) Springer Science+Business Media, LLC, part of Springer Nature 2020

Severe acute respiratory syndrome coronavirus 2 (SARS$\mathrm{CoV}-2$ ), a novel coronavirus, is the etiological agent causing the 2019 coronavirus disease (COVID-19) [1]. The COVID19 pandemic has produced a significant disruption to almost all aspects of life, including reshaping - at least temporarily-the ways in which HIV researchers interact with critical stakeholders: people living with HIV (PLWHIV), healthcare systems, and community organizations serving PLWHIV. COVID-19 initiated several disturbances in the social ecology so ardently studied by practitioners and represents both challenge and opportunity for community-engaged researchers. Despite the difficulty in pinpointing all impacts of COVID-19, interdisciplinary research is looking to historical data about the HIV pandemic in an attempt to estimate possible scenarios [2, 3]. For example, the initial HIV crisis affected households, businesses and governments from the loss of life, changes in the labor force and changes in public spending on healthcare [4]. COVID-19 is of particular

Ijeoma Opara

ijeoma.opara@stonybrook.edu

1 School of Social Welfare, Stony Brook University, 101 Nicolls Road, Health Sciences Center, Stony Brook, NY 11794-8231, USA

2 Department of Infectious Diseases and Microbiology, Graduate School of Public Health, University of Pittsburgh, 130 De Soto Street, Pittsburgh, PA 15261, USA

3 School of Nursing, University of Rochester Medical Center, 601 Elmwood Avenue, Box SON, Rochester, NY 14642, USA

4 Department of Psychology, University of Maryland, Baltimore County, 1000 Hilltop Circle, Baltimore, MD 21250, USA

5 Department of Social and Behavioral Sciences, Yale School of Public Health, Room 415, 60 College Street, New Haven, CT 06520, USA

6 Center for Interdisciplinary Research on AIDS, School of Public Health, Yale University, 135 College Street, Suite 200, New Haven, CT 06510-2483, USA interest due to the implication that immunocompromised persons may be at increased risk, particularly PLWHIV who are not virally suppressed, whether they have a reduced CD4 cell count or are not currently on antiretroviral therapy (ART) [5]. Further, key services relevant to HIV care and continuum outcomes may be limited due to prioritization of slowing the spread of COVID-19 [6].

As community-based participatory HIV researchers, our primary goal is to work collaboratively with PLWHIV and those most at-risk, in order to reduce and eliminate negative health outcomes. We work toward these goals by developing relationships with community partners (i.e., communitybased organizations [CBOs]) that serve PLWHIV and those at-risk for HIV directly, identifying barriers and facilitators to achieving viral suppression and prevention outcomes. Through this work, we have committed ourselves to provide the communities we serve with sustainable, culturally relevant strategies to educate and provide redress for the multifaceted causes of the HIV epidemic. We seek to strengthen the collective response to COVID-19 among HIV researchers by urging them to consider using collective resources strategically with community partners during this public health crisis.

Ecologically, COVID-19 and social distancing have impacts at almost every level relevant to research with populations living with or at risk for HIV. Individually, PLWHIV may be concerned that they are at increased risk for COVID19. Further, HIV is already associated with depression, loneliness and poor health outcomes among PLWHIV [7, 8] which may be exacerbated by social distancing guidelines. Dyadic considerations may include if serostatus concordant partners are living with HIV and undetectable, and concerns about intimate partner violence while sheltering in place [9]. At the institutional and community level, the closure of many businesses and CBOs may limit the supports available to those most in need. Indirect impacts of COVID-19 and social distancing, such as increased intimate partner violence, food insecurity, income insecurity, and economic 
shocks may further increase the needs and vulnerability of PLWHIV and those most as risk, as well as affect the priorities and focus of CBOs.

CBOs that primarily serve PLWHIV and those most atrisk for HIV often provide essential resources within the HIV care continuum such as HIV care management, medical care and mental health services (e.g., substance use prevention education and treatment). Furthermore, CBOs provide vital support in connecting PLWHIV to ancillary services such as rapid re-housing for those experiencing homelessness or housing instability. This is especially important as those living with HIV and experiencing homelessness are at the nexus of two groups requiring additional precautions for COVID-19 [10]. During this public health crisis, many CBOs are struggling to ensure continuity of services for clients, while monitoring the safety of employees and responding to overwhelming requests for information and technical support. Lastly, inconsistent and unclear messaging from government officials throughout the emerging crisis continues to stress an already patchwork system of resources. As with the early HIV epidemic, widespread misinformation regarding COVID-19 is of great concern [11, 12] and the lack of personal protective equipment and unclear strategy for screening threatens to reduce confidence in populations of color which already report medical mistrust, particularly among PLWHIV [13-15]. Given these considerations, it is imperative that the response of community-engaged researchers is robust.

We suggest four considerations for community-engaged HIV researchers in response to the COVID-19 pandemic and provide reasoning and examples for clarity.

\section{Maintain Bi-directional Communication with Community Partners to Assess and Strategize Around Needs}

It is clear that while this unprecedented situation has caused many agencies to alter their service provision, partnerships must be maintained. Conversations can center the needs of the community partner and revisit shared partnership aims in order to develop a mutually beneficial strategy. Researchers can inquiry about resource needs (e.g., materials, social, and individuals) or needs related to data collection in order to document how HIV-related needs are exacerbated (or curtailed) and/or the short and long-term ecological impacts of COVID-19 on PLWHIV. Further, the nature of COVID-19 is dynamic and fast-changing, which may require frequent and systematic check-ins with community partners to reevaluate community needs and research directions. Such regular check-ins will also provide more opportunities for community partners to engage academic researchers in communityled initiatives.

\section{Using a "push" Model Strategy to Disseminate Relevant Information to Communities}

Historically, research has used a "pull" model, where interested individuals sought out information in periodicals; however, researchers are beginning to use a "push" strategy where research is disseminated to interested parties through venues such as social media $[16,17]$. The rapid pace of developing information may be complicated for community partners to research and verify while simultaneously adjusting services for clients. Researchers, skilled in validating evidence, can provide this information to community agencies who may then disseminate via various social media platforms and online support groups. Such partnerships may maximize the penetration of evidence-based information by a source already deemed trustworthy by the client population.

\section{Creatively Sharing Resources with Community Partners}

Academic institutions have been successfully transitioning to virtual formats for weeks, and many are already conducting research, telehealth services and offering online resources to PLWHIV [18]. Significant variation in needs may exist among community partners during this period. Cohosting virtual meetings, particularly for community partners who may not readily have access to such virtual meeting platforms is one example of creatively leveraging resources to augment information sharing. Facilitating university affiliative status for community partners and technologic and infrastructure support will allow community partners to utilize online resources in the delivery of services and reduce power differentials between academic and community partners that serve as barriers to true community-based work.

\section{Providing a Path Forward}

COVID-19 has caused an increased amount of uncertainty for almost all sectors of society, and research is no exception [19]. As community-based researchers, we rely on partners and communities for data collection through many face-to-face methods (e.g., ethnography, observation) and some methods will transition with technology more readily than others. We recommend that researchers communicate that there will need to be a period to 
acknowledge the challenges brought by the pandemic and adjust accordingly. This may exist as not only an opportunity to validate existing relationships with community, but ultimately strengthen them as members of the partnership adjust together.

While these considerations are not without limitations, (e.g., there may be differing access to internet-capable technology by some community members and clients) these strategies may be critical in moving forward as there are early indications of racial and economic disparities amid the COVID-19 pandemic [20-22]. While engaging in research may not be the first priority of community partners or PLWHIV during a pandemic, providing them with an avenue to voice concerns, identify challenges to care continuum delivery, and inform future interventions fulfils our commitment to use engagement and investigation to provide sustainable tools at the community and policy levels.

\section{References}

1. World Health Organization. Naming the coronavirus disease (COVID-19) and the virus that causes it 2019. https://www.who. int/emergencies/diseases/novel-coronavirus-2019/technical-guida nce/naming-the-coronavirus-disease-(covid-2019)-and-the-virus -that-causes-it. Accessed 7 Apr 2020.

2. McKibbin WJ, Fernando R. The global macroeconomic impacts of COVID-19: Seven scenarios. 2020.

3. Whiteside A, Parker W, Schramm M. Managing the march of COVID-19: lessons from the HIV and AIDS epidemic. Afr J AIDS Res. 2020. https://doi.org/10.2989/16085906.

4. Haacker M. The macroeconomics of HIV/AIDS: International Monetary Fund. 2004

5. Centers for Disease Control and Prevention. What to know about HIV and COVID-19. 2020. https://www.cdc.gov/coronaviru s/2019-ncov/need-extra-precautions/hiv.html. Accessed 7 Apr 2020.

6. Jiang H, Zhou Y, Tang W. Maintaining HIV care during the COVID-19 pandemic. Lancet HIV. 2020. https://doi.org/10.1016/ S2352-3018(20)30105-3.

7. Bradley CD. Characterizing the expereince of loneliness among young black MSM ages 16-29 in the Chicago UConnect cohort study: Johns Hopkins University. 2019.

8. Grov C, Golub SA, Parsons JT, Brennan M, Karpiak SE. Loneliness and HIV-related stigma explain depression among older HIV-positive adults. AIDS Care. 2010;22(5):630-9.

9. Gupta AH, Stahl A. For abused women, a pandemic lockdown holds dangers of its own. The New York Times. 2020. https:// www.nytimes.com/2020/03/24/us/coronavirus-lockdown-domes tic-violence.html. Accessed 7 Apr 2020
10. Centers for Disease Control and Prevention. Responding to coronavirus disease 2019 (COVID-19) among people experiencing unsheltered homelessness 2020. https://www.cdc.gov/coronaviru s/2019-ncov/need-extra-precautions/unsheltered-homelessne ss.html. Accessed 7 Apr 2020.

11. Mian A, Khan S. Coronavirus: the spread of misinformation. BMC Med. 2020;18(1):1-2.

12. Gonçalves-Sá J. In the fight against the new coronavirus outbreak, we must also struggle with human bias. Nat Med. 2020;26:305.

13. Ball K, Lawson W, Alim T. Medical mistrust, conspiracy beliefs \& HIV-related behavior among African Americans. J Psychol Behav Sci. 2013;1(1):1-7.

14. Bogart LM, Wagner GJ, Green HD Jr, Mutchler MG, Klein DJ, McDavitt B, et al. Medical mistrust among social network members may contribute to antiretroviral treatment nonadherence in African Americans living with HIV. Soc Sci Med. 2016;164:133-40.

15. Galvan FH, Bogart LM, Klein DJ, Wagner GJ, Chen Y-T. Medical mistrust as a key mediator in the association between perceived discrimination and adherence to antiretroviral therapy among HIV-positive Latino men. J Behav Med. 2017;40(5):784-93.

16. Allen HG, Stanton TR, Flavia Di Pietro G. Social media release increases dissemination of original articles in the clinical pain sciences. PLoS ONE. 2013;8(7):e68914.

17. Klar S, Krupnikov Y, Ryan JB, Searles K, Shmargad Y. Using social media to promote academic research: identifying the benefits of twitter for sharing academic work. PLoS ONE. 2020;15(4):e0229446.

18. Marhefka S, Lockhart E, Turner D. Achieve research continuity during social distancing by rapidly implementing individual and Group videoconferencing with participants: key considerations, best practices, and protocols. AIDS Behav. 2020. https:// doi.org/10.1007/s 10461-020-02837-x.

19. Servick K, Cho A, Couzin-Frankel J, Guglielmi G. Coronavirus disruptions reverberate through research. Am Assoc Adv Sci. 2020. https://doi.org/10.1126/science.367.6484.1289.

20. Garg S, Kim L, Whitaker M, O'Halloran A, Cummings C, Holstein $\mathrm{R}$, et al. Hospitalization rates and characteristics of patients hospitalized with laboratory-confirmed coronavirus disease 2019-COVID-NET, 14 States, March 1-30, 2020. MMWR Morbidity and Mortality Weekly Report. 2020.

21. NYC Health. Age adjusted rate of the fatal lab confirmed COVID19 cases per 100,000 as of 6 April 2020. 2020. https://www1.nyc. gov/assets/doh/downloads/pdf/imm/covid-19-deaths-race-ethni city-04082020-1.pdf. Accessed 7 Apr 2020.

22. Valentino-DeVries J, Lu D, Dance GJX. Location data says it all: staying at home during coronavirus is a luxury. The New York Times. 2020.

Publisher's Note Springer Nature remains neutral with regard to jurisdictional claims in published maps and institutional affiliations. 